\title{
Non-Syndromic autosomal recessive deafness in Gaza strip: A study of five GJB2 Gene mutations
}

\author{
Badria F. Essammak ${ }^{1}$, Mohammed J. Ashour ${ }^{2}$, Fadel A. Sharif ${ }^{2, ~ *}$ \\ ${ }^{1}$ Faculty of Medicine, The Islamic University of Gaza, Palestine \\ ${ }^{2}$ Department of Medical Laboratory Sciences, Faculty of Health Sciences, The Islamic University of Gaza, Palestine \\ Email address: \\ fsharif@iugaza.edu.ps (F. A. Sharif), Fadelsharif@gmail.com (F. A. Sharif), bsammak@iugaza.edu.ps (B. F. Essammak), \\ mjashour@iugaza.edu.ps (M. J. Ashour)
}

\section{To cite this article:}

Badria F. Essammak, Mohammed J. Ashour, Fadel A. Sharif. Non-Syndromic Autosomal Recessive Deafness in Gaza Strip: A Study of Five GJB2 Gene Mutations. International Journal of Genetics and Genomics. Vol. 2, No. 5, 2014, pp. 92-96. doi: 10.11648/j.ijgg.20140205.13

\begin{abstract}
Hearing loss is a common, pan-ethnic and highly heterogeneous sensory disorder with an incidence of around 1 in 1000 infants. Genetic causes are thought to be responsible for more than $60 \%$ of the cases with the majority of non-syndromic hearing impairment being inherited in an autosomal recessive pattern. The gene that is most frequently mutated in autosomal recessive non-syndromic hearing loss (ARNSHL) is gap junction protein beta-2 (GJB2) which codes for connexin 26 (Cx26). Cx26 plays a key role in potassium homeostasis, which is essential for sound transduction. The aim of this study was to determine the common GJB2 gene mutations in 70 patients suffering from ARNSHL in Gaza strip. The patients were screened for five GJB2 gene mutations namely, c.35delG, c.167delT, c.-23+1G $>$ A, c.229T $>$ C (p.Trp77Arg) and c.235delC. Study results revealed that GJB2 mutations account for at least $35.7 \%$ of the ARNSHL with mutant allele frequency of $0.4 \%$. The most frequently encountered mutation was c.35delG which accounted for $35.7 \%$ of the ARNSHL cases in either homozygous $(34.3 \%)$ or heterozygous $(1.4 \%)$ form and represented about $80.5 \%$ of all the detected mutations. The second most frequent mutation was c.235delC which was found only in heterozygous form. The third mutation was c. $-23+1 \mathrm{G}>\mathrm{A}$ which was identified in only one subject $(1.4 \%)$ in a compound heterozygous form along with c.35delG. The c.167delT and p.Trp77Arg mutations were not observed in our patients. We conclude that there is a significant contribution of GJB2 mutations to congenital ARNSHL in the Palestinian population of Gaza strip. Screening for GJB2 mutations particularly, c.35delG, c. 235 delC and c. $-23+1 \mathrm{G}>$ A should be offered to ARNSHL patients to confirm diagnosis of their congenital deafness, to deliver proper genetic counseling for the affected individuals and their families and to help them benefit from prenatal and preimplantation genetic diagnosis.
\end{abstract}

Keywords: ARNSHL, Cx26, GJB2, Mutation, PCR-RFLP, Gaza Strip

\section{Introduction}

Hearing loss is the most prevalent form of sensory impairment in humans, with approximately 1 in 1000 infants being born with a serious hearing deficit (Shahin et al., 2002) Hereditary hearing loss can be subdivided into two types: syndromic or non-syndromic. The syndromic type is associated with other distinctive clinical features beyond deafness and accounts for about $30 \%$ of hereditary congenital deafness. The non-syndromic type, in which deafness is the only clinical manifestation, represents the other $70 \%$ (Matsunaga, 2009). Regarding non-syndromic hearing impairment, autosomal recessive form is the most frequent, accounting for $75-85 \%$ of the cases [Snoeckx et al., 2005; Ibrahim et al., 2011). Eighty (80) loci are already described for non-syndromic autosomal recessive deafness (http://hereditaryhearingloss.org).

The different loci for the numerous forms of deafness have been called DFN (for deafness) and are numbered in chronological order of discovery. The first ARNSHL locus, DFNB1 accounts for at least $50 \%$ of this type of hearing loss (Mukherjee et al., 2003). At chromosome 13q11-q12, DFNB1 locus comprises Gap Junction $\beta-2$ (GJB2) and Gap Junction $\beta-6$ (GJB6) genes that code for connexin 26 and connexin $30(\mathrm{Cx} 30)$, respectively (Rodriguez et al., 2011). On the other hand, DFNA refers to autosomal dominant deafness loci. 
Connexin 26 is one member of a family of related gapjunction channel forming proteins (Mukherjee et al., 2003). These gap junction proteins oligomerize as hexamers to form transmembrane channels called connexons. Connexons from the cell membranes interdigitate to form direct intercellular communications pathways, the gap junction channels (RamShankar et al., 2003).

Human connexins are classified either by molecular mass $(26-59 \mathrm{kDa})$ or by sequence similarities into 5 subgroups: gap junction $\alpha$ (GJA), gap junction $\beta$ (GJB), gap junction $\gamma$ (GJC), gap junction $\delta$ (GJD) and gap junction $\varepsilon$ (GJE). Sensorineural hearing loss is caused by mutations in the gap junction genes encoding the $\beta$ connexins (Mukherjee et al., 2003).

GJB2, the gene encoding human connexin 26 (Cx26), was the first gene to be linked to an autosomal recessive form of deafness, DFNB1 (Kelsell et al., 1997). GJB2 gene has 5500 bp and a single coding exon (exon 2), in a total of two exons. More than 200 different pathogenic mutations were identified in this gene that account for $10-40 \%$ of congenital deafness (Tang et al., 2006; Falah et al., 2011). GJB2 mutation spectrum differs among various populations or even within a particular country. Therefore, it is necessary to establish the frequency of GJB2 mutations in any population (Bonyadi et al., 2011).

Mutations at the DFNB1 locus can be classified into two groups: (i) those that affect the coding sequence of $G J B 2$, and (ii) those that lie outside the coding sequence of $G J B 2$ and affect the expression and/or regulation of this gene (Gandia et al., 2013).

This study was designed in order to determine for the first time the common mutations in connexin 26 gene in non syndromic autosomal recessive deafness cases in Gaza strip.

\section{Materials and Methods}

\subsection{Subjects and Selection Criteria}

The population of this descriptive analytical study consisted of 70 deaf patients. The subjects were recruited from three Gaza Strip hearing loss centers: Mustafa Sadiq Rafii Secondary School for the Deaf, Atfaluna Society for the Deaf Children and Basma Center for Audiology and Speech Therapy. The participants were from both genders and their age ranged from 2-27 years and they all suffered from prelingual severe to profound bilateral hearing loss. Apart from their deafness the subjects did not have any other remarkable health problems. The study protocol was presented for approval to the Ministry of Education and to the Administrations of the three centers. Approval and written consent of patients and/or their parents was also taken. In order to ensure that hearing loss in the study subjects is most probably of the autosomal recessive non-syndromic type, an interview was conducted with each patient and/or his/her family to help exclude other hearing loss causes.

\subsection{Mutation Analysis}

Anticoagulated venous blood $(\sim 2 \mathrm{ml})$ was collected from each patient. Genomic DNA was prepared from peripheral blood lymphocytes using Wizard Genomic DNA Purification Kit (Promega, USA) according to the manufacturer's protocol. Extracted DNA was used in screening for the selected mutations. PCR-Restriction fragment length polymorphism (PCR-RFLP) analyses were performed for detecting all five mutations as previously described by other investigators and as indicated in Table 1. Restriction enzymes and PCR primers were purchased from Promega (USA). Digested PCR products were analyzed by electrophoresis in a $1.5 \%$ agarose gel containing ethidium bromide, and the results were documented using a gel documentation system.

Table 1. Primer sequences, restriction enzymes and allele designation used for identifying the five GJB2 mutations

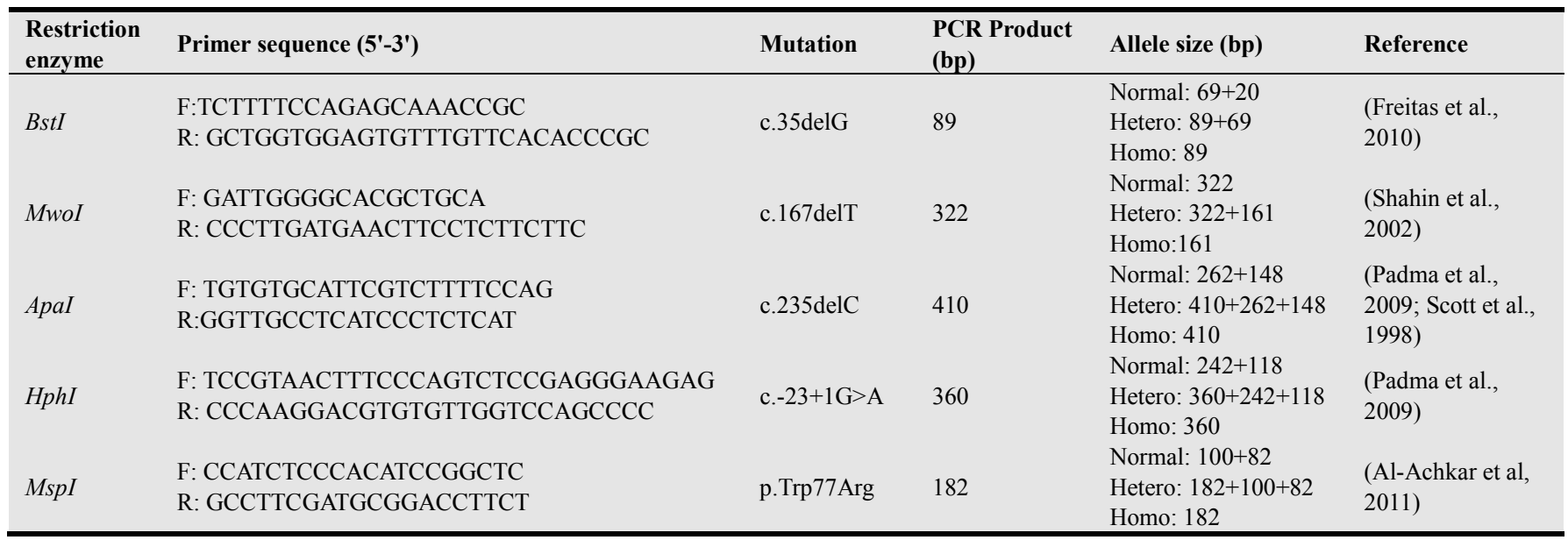

DNA samples were first screened for c.35delG and c.167delT mutations and when no c. $35 \mathrm{delG}$ or c. $167 \mathrm{delT}$ mutation was detected, screening was continued for the c.235delC, IVS1+1 G>A and p.Trp77Arg mutations. The rationale behind selecting those mutations is based on their common presence in the West Bank part of Palestine (Shahin et al., 2002) and in neighboring Arab countries e.g., Lebanon, Syria and Jordan (Mahayri and Monem, 2012; Medlej- 
Hashim et al., 2002; Mustafa et al., 2001) which are believed to be historically related to our population.

\section{Results}

This study investigated five GJB2 gene mutations associated with non-syndromic autosomal recessive deafness in 70 deaf patients in Gaza strip. Among the deaf patients, 37 $(53 \%)$ were males and $33(47 \%)$ were females. The age of patients ranged from 2 to 27 years.

The results of the interview revealed that consanguineous marriage is common between the parents of the patients $(76 \%)$, and that there is a relevant family history in the family of the father $(34 \%)$ or the mother $(33 \%)$. Additionally, $63 / 70(90 \%)$ of the patients' parents had normal hearing. Available data for 6 of the remaining 7 patients showed that their maternal and paternal grandparents had normal hearing.
Therefore, interview outcomes allowed us to consider almost all the patients as having non-syndromic autosomal recessive hearing loss.

Of the 70 deaf patients, $31(44.3 \%)$ were found to harbor GJB2 mutation in homozygous, compound heterozygous or heterozygous form. However, $39(55.7 \%)$ of the study subjects failed to show any of the tested mutations.

GJB2 c.35delG was the most frequently encountered mutation where 25 of the 70 probands $(35.7 \%)$ were found to be either homozygous $(34.3 \%)$ or heterozygous $(1.4 \%)$ for this mutation. Heterozygosity was recorded in only one proband who was compound heterozygous for c.35delG/ c.$23+1 \mathrm{G}>\mathrm{A}$. The second prevalent GJB2 mutation c. $235 \mathrm{delC}$, was detected only in heterozygous form (one mutant copy) in six probands $(8.6 \%)$. None of the 70 samples showed the c.167delT or the p.Trp77Arg mutation. Frequency of the detected mutations is summarized in Table 2.

Table 2. Frequency of mutations in CX26 in ARNSHL patients in Gaza strip

\begin{tabular}{|c|c|c|c|}
\hline Mutation & Genotype & Frequency No. (\%) & Allele frequency \\
\hline c.35delG & c. 35 delG/c. 35 delG c. 35 delG/ C. $-23+1 \mathrm{G}>\mathrm{A}$ & $24(34.3 \%) 1(1.4 \%)$ & 0.35 \\
\hline c. $-23+1 \mathrm{G}>\mathrm{A}$ & c. $-23+1 \mathrm{G}>\mathrm{A} / \mathrm{c} .35 \mathrm{delG}$ & $1(1.4 \%)$ & 0.007 \\
\hline c. $235 \mathrm{delC}$ & c.235delC/unknown & $6(8.6 \%)$ & 0.043 \\
\hline c. $167 \mathrm{delT}$ & Not detected & - & - \\
\hline p.Trp77Arg & Not detected & - & - \\
\hline Total & & $31(44.3 \%)$ & 0.4 \\
\hline
\end{tabular}

\section{Discussion}

This work investigated five GJB2 mutations in Gaza strip Palestinian families with presumable ARNSHL. The results revealed that the GJB2 mutations were evident in 31 (44.3\%) probands. When compared to its frequency in other populations, this result is among the highest GJB2 mutation rates reported so far.

ARSNHL patients from different ethnic groups also show variation in terms of the frequency of individual mutations. Our results demonstrated that c.35delG accounts for a significant proportion $(\sim 80.5 \%)$ of the pathogenic $G J B 2$ alleles. This mutation is the commonly encountered GJB2 mutation in Caucasians however, it is very rare in Asian patients (Cifuentes et al., 2013).

On the other hand, the second most common mutation observed in this study c. $235 \mathrm{delC}$ represents the most frequent mutation in some Asian populations, Japan in particular (Abe et al., 2000), whereas it is rare in Africans (Chan and Chang, 2013) and Indonesians (Gaffar et al., 2009).

Likewise, c.167delT which was not detected in our patients is predominant in Ashkenazi Jews (Morell et al., 1998). Interestingly, Shahin et al., (2002) detected this mutation in a group of Palestinians from Bethlehem (Shahin et al., 2002) indicating that variation in GJB2 mutant allele frequency may also be evident in groups of the same population.

The third detected mutation was the splicing mutation c.$23+1 \mathrm{G}>\mathrm{A}$ which was found only in one patient in compound heterozygous form with c.35delG. This result is similar to that reported in many Arab populations (Shahin et al., 2002;
Snoeckx et al., 2005; Riahi et al., 2013). This mutation is frequent in ARNSHL cases of Iranian Azeri Turkish population, Eastern Europe, Turkey and Kurdish population of Iran (Bonyadi et al., 2011; Mahdieh et al., 2004; Seeman and Sakmaryova, 2006; Sirmaci et al., 2006; Toth et al., 2007).

The trend is not different for mutation p.Trp77Arg which also was not detected in our study. This mutation is commonly encountered in certain populations e.g., Spanish and Cubans (Perea et al., 2007), and is detected in low frequency in Arabs (Al-Qahtani et al., 2010).

Variation between different studies in terms of the frequency and type of GJB2 mutations associated with ARNSHL could be due to several reasons including: sample size (higher sample size increases the chance of detecting rare or exceptionally low mutations), precision of genotyping method employed, selection criteria of the patients investigated, rate of consanguineous marriage, and population genetic structure in terms of the type of circulating founder GJB2 mutant alleles.

In more than half of the examined patients none of the five screened GJB2 mutations could be detected and in 6 patients only one mutant allele (c.235delC) could be identified. This finding is comparable to those found by other investigators where they showed that their ARNSHL patients harbored only one mutated allele in the GJB2 gene (Kenneson et al., 2002). This could be due to three possible causes: (i) presence of other mutations in the coding or regulatory regions of $G J B 2$; (ii) mutations (particularly deletions) in the contiguous GJB6 gene which has been shown to co-occur in GJB2 heterozygotes and, (iii) mutation in other hearing loss 
loci. Work is ongoing to find other pathogenic alleles by sequence analysis of the GJB2 gene and screening for GJB6 gene mutations.

\section{Conclusion}

There is a significant contribution of GJB2 mutations to congenital ARNSHL in the Palestinian population of Gaza strip. By screening GJB2 c. $35 \mathrm{delG}$, c. $235 \mathrm{delC}$ and C.$23+1 \mathrm{G}>\mathrm{A}$, the molecular cause in as high as $35.7 \%$ of ARNSHL patients of Gaza strip can be identified. Moreover, defining the mutation responsible for ARNSHL is crucial for confirming diagnosis and delivering proper genetic counseling for the affected individuals and their families.

\section{Acknowledgments}

Special gratitude goes to Gaza Strip hearing loss centers, especially Mustafa Sadiq Rafii Secondary School for the Deaf, Atfaluna Society for the Deaf Children, and Basma Center for Audiology \& Speech Therapy. And special thanks to all the deaf participants and their families, for their cooperation.

\section{Funding}

This work was partially supported by the Scientific Research Council [Scientific Research Grant 2014-2015], Ministry of Education and Higher Education, Gaza, Palestine.

\section{Author Disclosure Statement}

The authors hereby declare that no competing interests exist.

\section{References}

[1] Abe S, Usami SH, Shinkawa H, Kelley PM, Kimberling WJ. Prevalent connexin 26 gene (GJB2) mutations in Japanese. J Med Genet 2000, 37:41-43.

[2] Al-Achkar W, Moassass F, Al-Halabi B, Al-Ablog A. Mutations of the Connexin 26 gene in families with nonsyndromic hearing loss. Molecular Medicine Reports 2011, 4: 331-335.

[3] Al-Qahtani MH, Baghlab I, Chaudhary AG, Abuzenadah AM, Bamanie A, Daghistani KJ, et al. A. Spectrum of GJB2 Mutations in a Cohort of Non-syndromic Hearing Loss Cases from the Kingdom of Saudi Arabia. Genetic Testing and Molecular Biomarkers 2010, 14(1):79-83.

[4] Bonyadi M, Fotouhi N, Esmaeili M. Prevalence of IVS1+1G $>$ A mutation among Iranian Azeri Turkish patients with autosomal recessive non-syndromic hearing loss (ARNSHL). International Journal of Pediatric Otorhinolaryngology 2011, 75: 1612-1615.

[5] Chan DK and Chang KW. GJB2-Associated Hearing Loss: Systematic Review of Worldwide Prevalence, Genotype, and Auditory Phenotype. Laryngoscope 2013, 124(2): E34-53.
[6] Cifuentes L, Arancibia M, Torrente M, Acuña M, Farfán C, Ríos C. Prevalence of the $35 \mathrm{delG}$ mutation in the GJB2 gene in two samples of non-syndromic deaf subjects from Chile. Biol. Res. 2013: 46(3) Santiago.

[7] Falah M, Houshmand M, Akbaroghli S, Mahmodian S, Ghavami Y, Farhadi M. Profile of Iranian GJB2 Mutations in Young Population with Novel Mutation. Iranian Journal of Basic Medical Sciences 2011, 14 (3): 213-218.

[8] Freitas Cordeiro-Silva M, Barbosa A, Santiago M, Provetti M, Rabbi- Bortolini E. Prevalence of $35 \mathrm{delG} / G J B 2$ and del (GJB6-D13S1830) mutations in patients with non-syndromic deafness from a population of Espírito Santo - Brazil. Braz J Otorhinolaryngol 2010, 76(4):428-32.

[9] Gaffar M, Budu, Kuhuwael FG, Yusuf I. A Polymerase Chain Reaction-Restriction Fragment Length Polymorphism (PCRRFLP) Analysis of Connexin 26 (GJB2) Gene Common Mutation (235delC) In Indonesian Patients with Prelingual Non-syndromic Sensorineural Hearing Loss: A Preliminary Study. The Open Otorhinolaryngology Journal 2009, 3, 16-20.

[10] Gandía M, del Castillo FJ, Rodríguez-Álvarez FJ, Garrido G, Villamar M., Calderón M, et al. A Novel Splice-Site Mutation in the GJB2 Gene Causing Mild Postlingual Hearing Impairment. PLoS ONE 2013, 8(9): e73566.

[11] Ibrahim SM, Ali M, Ahmad S, Ali L, Muhammad N, Tareen R, et al. Autosomal Recessive Deafness is Heterogeneous in Pakistani Pakhtun Population. Curr. Res. J. Biol. Sci. 2011, 3(1): 17-24.

[12] Kelsell DP, Dunlop J, Stevens HP, Lench NJ, Liang JN, Parry $\mathrm{G}$, et al. Connexin 26 mutations in hereditary non-syndromic sensorineural deafness. Nature 1997, 387 (6628): 80-83.

[13] Kenneson A, Naarden Braun KV, Boyle C. GJB2 (connexin 26) variants and non-syndromic sensorineural hearing loss: A HuGE review. Genet Med. 2002, 4 (4): 258-274.

[14] Mahdieh N, Nishimura C, Ali-Madadi K, Riazalhosseini Y, Yazdan $\mathrm{H}$, Arzhangi $\mathrm{S}$, et al. The frequency of GJB2 mutations and the $\Delta$ (GJB6-D13S1830) deletion as a cause of autosomal recessive non-syndromic deafness in the Kurdish population. Clinical Genetics 2004, 65(6): 506-508.

[15] Mahyari ZN and Monem FS, GJB2 gene mutations in Syrians with sensorineural hearing loss. Middle East Journal of Medical Genetics 2012, 1(2):80-84.

[16] Matsunaga T. Value of genetic testing in the ontological approach for sensorineural hearing loss. Keio J Med 2009, 58 (4): $216-222$.

[17] Medlej-Hashim M, Mustapha M, Chouery E, Weil D, Parronaud J, Salem N, Delague V et al. Non-syndromic recessive deafness in Jordan: mapping of a new locus to chromosome $9 \mathrm{q} 34.3$ and prevalence of DFNB1 mutations. European Journal of Human Genetics 2002, 10: 391-394.

[18] Morell RJ, Kim HJ, Hood LJ, Goforth L, Friderici K, Fisher R, et al. Mutations in the Connexin 26 Gene (GJB2) Among Ashkenazi Jews with Non-syndromic Recessive Deafness. The New England Journal of Medicine 1998, 339 (21): 15001505 .

[19] Mukherjee M, Phadke SR, and Mittal B. Connexin 26 and autosomal recessive non-syndromic hearing loss. Department of Medical Genetics, Sanjay Gandhi Postgraduate Institute of Medical Sciences, Lucknow, India 2003, 9 (2): 40-50. 
[20] Mustapha M, Salem N, Delague V, Chouery E, Ghassibeh M, Rai M, Loiselet $\mathrm{J}$ et al. Autosomal recessive non-syndromic hearing loss in the Lebanese population: prevalence of the $30 \mathrm{delG}$ mutation and report of two novel mutations in the connexin 26 (GJB2) gene. J Med Genet 201, 38: e36.

[21] Padma G, Ramchander PV, Nandur UV, Padma T. GJB2 and GJB6 gene mutations found in Indian probands with congenital hearing impairment. Journal of Genetics 2009, 88( 3): 267-272.

[22] Perea Y, Mato J, Amores I, Ferreira R. Study of six mutations in the GJB2 gene in Cuban patients with non-syndromic sensorineural deafness. Biotecnología Aplicada 2007, 24:241245 .

[23] RamShankar M, Girirajan S, Dagan O, Ravi Shankar HM, Jalvi R, Rangasayee R, Avraham KB , Anand A. Contribution of connexin 26 (GJB2) mutations and founder effect to nonsyndromic hearing loss in India. J Med Genet 2003, 40:e68.

[24] Riahi Z, Hammami H, Ouragini H, Messai H, Zainine R, Bouyacoub Y, et al. Update of the spectrum of GJB2 gene mutations in Tunisian families with autosomal recessive nonsyndromic hearing loss. Gene 2013, 525(1):1-4.

[25] Rodríguez-Paris J, Tamayo ML, Gelvez N, Schrijver I. AlleleSpecific Impairment of GJB2 Expression by GJB6 Deletion del(GJB6-D13S1854). PLoS ONE 2011, 6(6): e21665.

[26] Scott DA, Kraft ML. Carmi R, Ramesh A, Elbedour K, Yairi Y, et al. Identification of mutations in the connexin 26 gene that cause autosomalrecessive non-syndromic hearing loss. Hum Mutat, 1998, 11(5):387-394.

[27] Seeman, P. and Sakmaryova, I. (2006). High prevalence of the IVS1-1G to A/GJB2 mutation among Czech hearing impaired patients with monoallelic mutation in the coding region of the GJB2. Clin Genet, 69: $410-413$.

[28] Shahin H, Walsh T, Sobe T, Lynch E, Claire KM, Avraham $\mathrm{KB}$, et al. Genetics of congenital deafness in the Palestinian population: multiple connexin 26 alleles with shared origins in the Middle East. Hum Genet 2002, 110:284-289.

[29] Sirmaci A, Akcayoz-Duman D, Tekin M. The c.IVS1+1G $>$ A mutation in the GJB2 gene is prevalent and large deletions involving the GJB6 gene are not present in the Turkish population. J Genet 2006, 85:213-216.

[30] Snoeckx RL, Hassan DM, Kamal NM, Den Bogaert KV, Camp GV. Mutation Analysis of the GJB2 (Connexin 26) Gene in Egypt. Human Mutation 2005, 26 (1): 60-61.

[31] Tang HY, Fang P, Ward PA, Schmitt E, Darilek S, Manolidis S, et al. DNA sequence analysis of GJB2, encoding connexin 26: Observations from a population of hearing impaired cases and variable carrier rates, complex genotypes, and ethnic stratification of alleles among controls. Am J Med Genet Part A 2006, 140A:2401-2415.

[32] Toth T, Kupka S, Haack B, Fazakas F, Muszbek L, et al. Coincidence of mutations in different connexin genes in Hungarian patients. Int J Mol Med 2007, 20: 315-321. 